\title{
TRANSIENT STABILITY ENHANCEMENT USING ARTIFICAL INTELLIGENCE BASED GOVERNOR CONTROLLER
}

\author{
M. Z. El-Sadek \\ Electrical Engineering Department, Faculty of Engineering, \\ Assiut , Egypt \\ Gaber Shabib \\ Electrical Engineering Department, High Institute of Energy, \\ Aswan, Egypt \\ Email: gabershabib@yahoo.com

\section{Wael M. Soliman} \\ High Dam Hydropower Plant, Hydro Power Generation \\ Company, Aswan, Egypt
}

(Received January 15, 2006 Accepted April 15, 2006)

The paper investigates the application of a fuzzy logic - based governor controller as a technique of artificial intelligence techniques for stability enhancement of a multimachine power system. A fuzzy controller is designed to operate in real time to improve each generating unit transients in a multimachine system through the governor loop. The fuzzy controller requires two inputs signals, speed deviation and acceleration of the machine and generates one output as a supplementary signal into the governor loop when the excitation system is fixed. The developed fuzzy controller, whose control signals are adjusted using on line measurements, offers better damping effects for generator oscillations under large disturbances compared to turbine speed governor with conventional controller. Computer simulations of a 3 unit power system show that employing this type of control is effective in reducing excessive over and under frequency deviations.

\section{NOMENCALTURE}

$\mathrm{x}_{\mathrm{d}}, \mathrm{x}_{\mathrm{q}} \quad \mathrm{d}$ and $\mathrm{q}$ axis synchronous reactance

$\mathrm{x}_{\mathrm{d}}^{\prime}, \mathrm{x}_{\mathrm{q}}^{\prime} \quad \mathrm{d}$ and $\mathrm{q}$ axis transient reactance

$\mathrm{T}_{\mathrm{do}}^{\prime}, \mathrm{T}_{\mathrm{qo}}^{\prime} \quad \mathrm{d}$ and $\mathrm{q}$ axis open circuit transient constants

$\mathrm{R}_{\mathrm{a}} \quad$ armature resistance

$\mathrm{V}_{\mathrm{d}}, \mathrm{V}_{\mathrm{q}} \quad \mathrm{d}$ and $\mathrm{q}$ axis components of the generator terminal voltage

$I_{d}, I_{q} \quad d$ and $q$ axis components of the generator terminal current

$\dot{\mathrm{E}}_{\mathrm{d}}, \dot{\mathrm{E}}_{\mathrm{q}} \quad \mathrm{d}$ and $\mathrm{q}$ axis components of the transient emf of the generator 


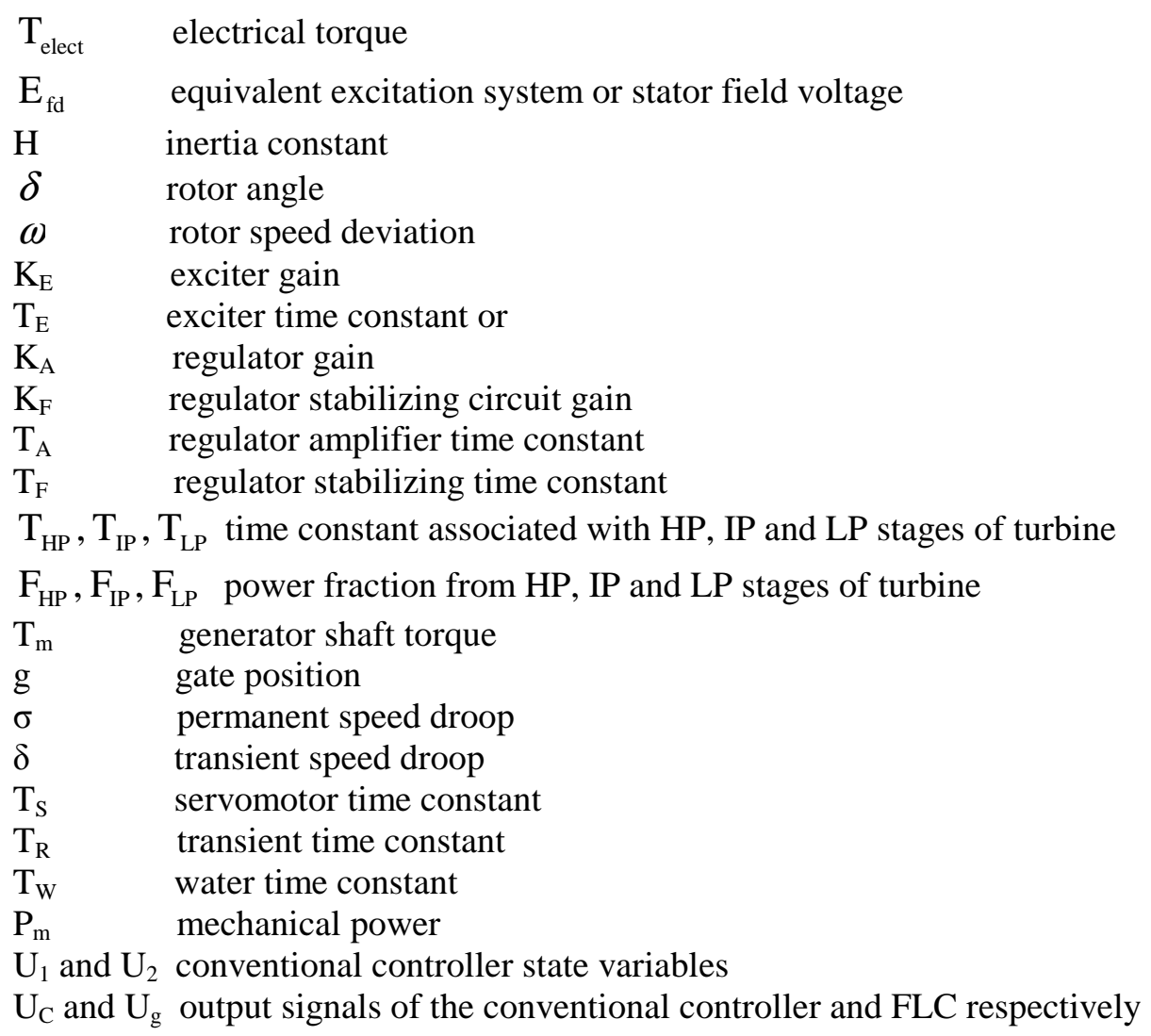

\section{INTRODUCTION}

In recent years, considerable attention has been directed towards the problem of improved designing of turbine governors, because of its influence on the dynamic performance of hydro and steam power plants. Until recently, analog devices have dominated the scene of generating unit controllers. Digital governors opened the door for implementing more complex algorithms due to their flexibility. As a result the speed loop started interfering with the excitation loop, so that mutual interaction of these control loops provided possibilities for obtaining better transients and wider stability margins $[1,2]$.

In addition, there has been considerable interest in the application of artificial intelligence control techniques to design nonlinear controllers for modern large interconnected power system [3,4]. The objective is to extend the operational margins of stability to enhance transient stability. Recent development in intelligence control theory and digital technology shows that substantial improvements may be achieved using such advanced techniques, whereas the intelligent control is introduced in power system studies to overcome inherent complexities and uncertainties that are always present in a variety of form $[5,6,7]$.

A 9 - bus three machine power system has been simulated and its results have been validated. Each machine of the multimachine power system is designed using fuzzy 
controller in the governor control loop. Each controller employed local variables only. The proposed controllers process excellent performance. These results are demonstrated by computer simulation studies and compared with turbine speed governor with conventional controller.

\section{TURBINE SPEED GOVERNOR}

Turbine speed governor [8] depends on its parameters responses only to improve the performance of governor to reduce the system oscillations. Figures 1, 2 show the hydraulic turbine speed governor and the steam turbine speed governor respectively. The mathematical models of the synchronous machine, hydraulic and steam turbine speed governor and the second order of voltage regulator all are described in Appendix A.

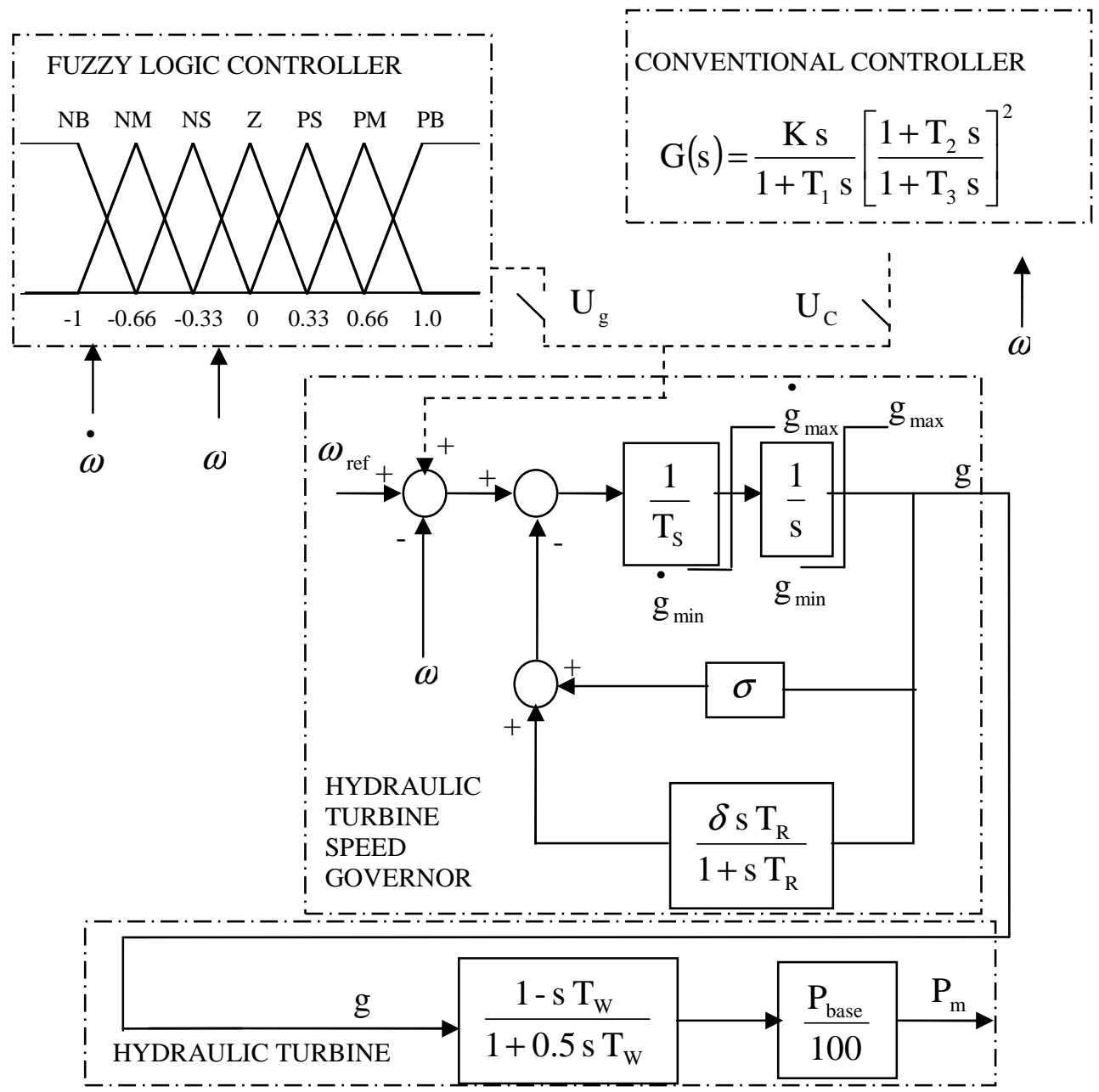

Fig. 1: Hydraulic turbine speed governor. 


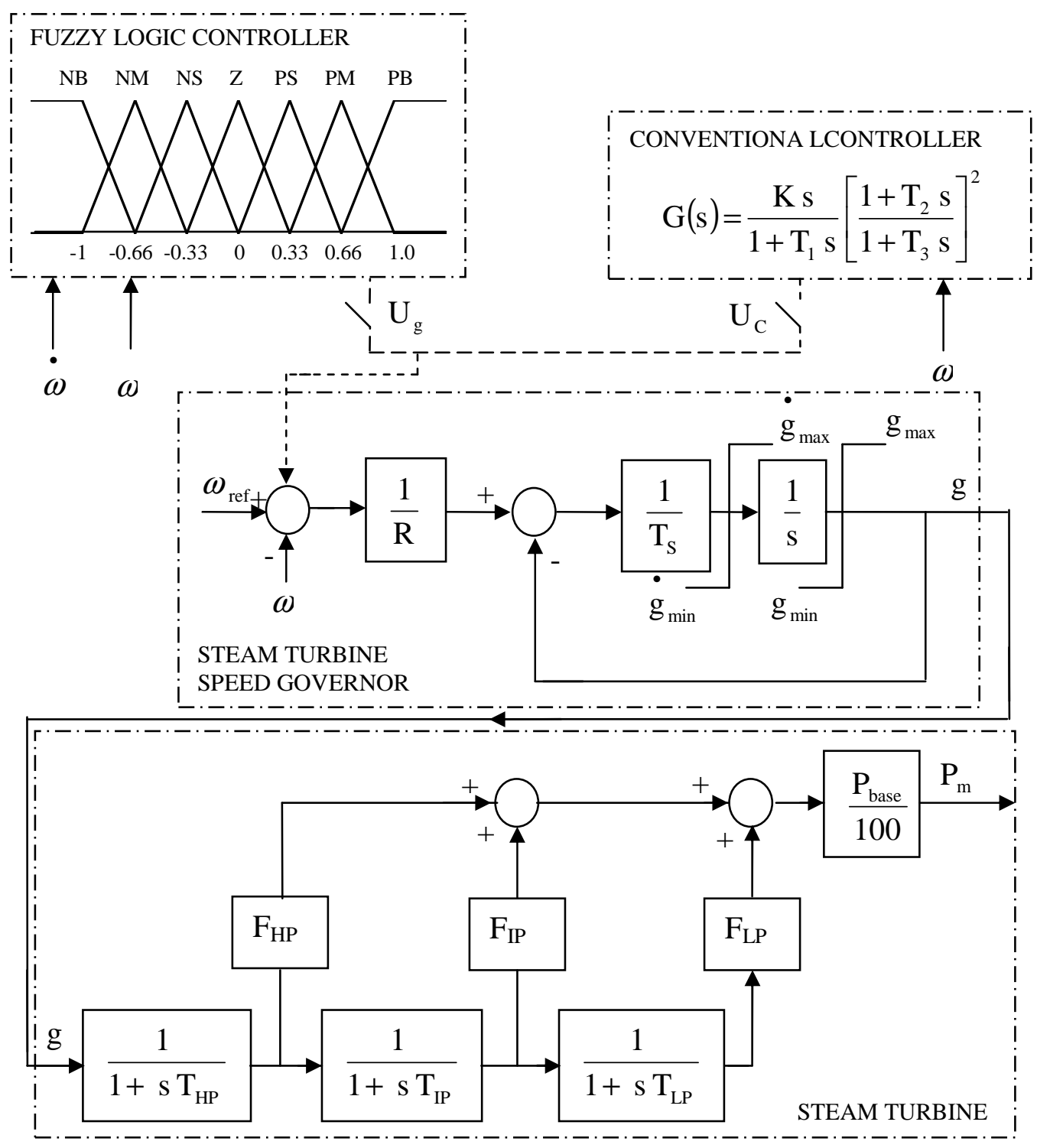

Fig. 2: Steam turbine speed governor.

\section{TURBINE SPEED GOVERNOR WITH CONVENTIONAL CONTROLLER}

Turbine speed governor with conventional controller is used to enhance damping of the electric power system oscillations. In this paper the block diagram of the conventional controller is shown in figure $\mathbf{3}$ and the transfer function is of the form [9]:

$$
G(s)=\frac{K s}{1+T_{1} s}\left[\frac{1+T_{2} s}{1+T_{3} s}\right]^{2}
$$


Where; The first factor on the right of (1) is a reset factor that is used to washout the compensating effect after a time $\mathrm{T}_{1}$ with stabilizer gain $\mathrm{K}$. And the second factor is lead - lag compensator. The input to conventional controller is the speed signal $\Delta \omega$ which can be computed directly from real time measurements and the set point. This is shown in figure 1 and figure 2. Its output ' $U_{C}$ ' is injected at the input sumner of the speed governor as a supplementary control signal to the governor control loop. The mathematical model is described in Appendix $\mathrm{I}_{\text {. }} \mathrm{U}_{1}$ and $\mathrm{U}_{2}$ represent the conventional controller state variables, $U_{\mathrm{C}}$ represents the output signal of the conventional controller.

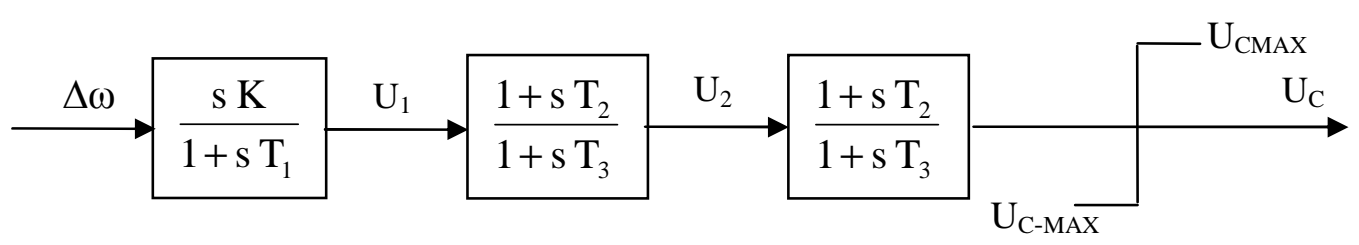

Fig. 3: Block diagram of the conventional controller.

\section{TURBINE SPEED GOVERNOR FUZZY LOGIC CONTROLLER}

Many authors presented mechanical hydraulic speed governor models for each of the hydraulic and steam turbine in power system studies [10, 11]. In this study, the fuzzy logic technique has applied for controlling the multimachine power system through their governing systems of their hydraulic and steam turbines. The proposed fuzzy logic governor controller has two inputs speed deviation $\Delta \omega_{j}$ and $\Delta \omega_{j}^{\prime}$ acceleration selected for machine \# $\mathrm{j}$ in a multimachine power system. This proposed controller has a single output control signal $\mathrm{U}_{\mathrm{g}}$, which applied to the summing point of the governor loop to produce a significant damping of the electromechanical oscillations after disturbances, and hence to improve the transient and dynamic performance of the multimachine system. Figure 1,2 show mechanical hydraulic speed governor for hydraulic turbine and steam turbine with fuzzy logic controller which produce a fuzzy logic control signal respectively.

\subsection{Structure of Fuzzy Controller}

In recent years, various fuzzy logic controllers have been developed based on fuzzy set theory for different applications [12]. Figure 4 illustrate the basic configuration of the fuzzy controller, where $e=r-y$, y is the output of controller plant, $r$ is the set point, $\mathrm{e}$ is the derivative of $\mathrm{e}$.

The fuzzy controller provides an algorithm, which can convert the linguistic control strategy based on expert knowledge into an automatic control strategy. Fuzzy logic controller consists of three main stages; the fuzzification process, inference (rule base) and defuzzification process. 


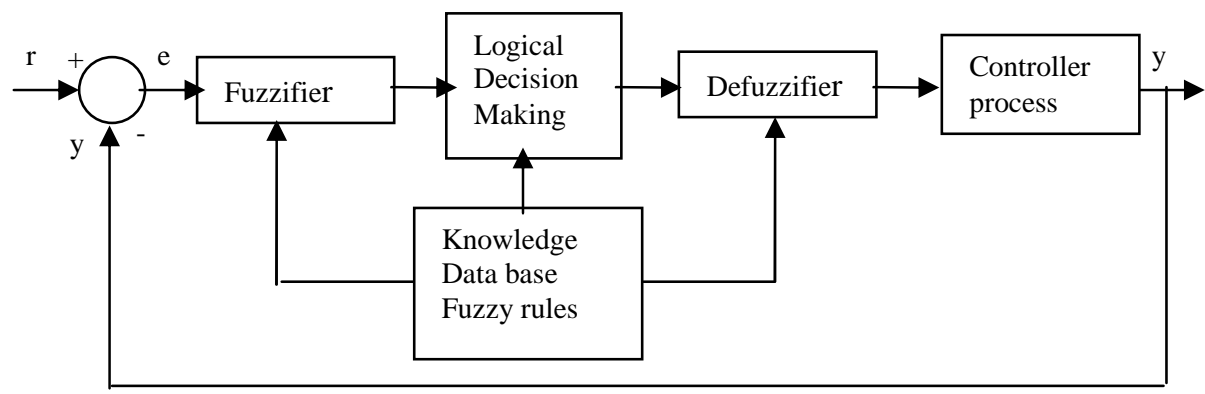

Fig. 4: Structure of fuzzy controller.

\subsection{Fuzzy Logic Control Design}

There are some steps showing how to develop a fuzzy model from concept to implementation. We broke fuzzy model development into seven manageable steps illustrated in [13], and summarized as follows:

\subsubsection{System description}

Define how the fuzzy model fits into the total system solution. Describe how the system should working in plain language. Of course, this first step is common to all problem solving. The system description needs only to express the general working of the system. The point is to capture the essence of the problem by identifying inputs, outputs, and their relationship to each other.

\subsubsection{Specification of input and output variable ranges}

Identify extreme ranges of the all inputs and outputs. Those extreme values provide good limits for a fuzzy variable's universe of discourse, for each of the input and output variables with one normalized universe of discourse $(-1,+1)$ are used here. Define the universes of discourse for all fuzzy variables. Thought must be given to input resolution, sensors, and output format.

\subsubsection{Membership function partitioning}

Partition each fuzzy variable into overlapping membership functions. Decide on number, shape, location, symmetry, and overlap. Seven linguistic variables for each of the input and output variables with one normalized universe of discourse are used to describe them. These are NB(Negative Big), NM(Negative medium), NS(Negative Small), Z(Zero), PS(Positive Small), PM(Positive Medium), PB(Positive Big). Each fuzzy variable is a member of the subsets with a degree of membership $\mu$ (e) and $\mu$ (e) varying between 0 and 1 . After specifying the fuzzy sets, it is required to determine the membership functions for these sets. Triangular - shaped function is used to define the degree membership of the continuous control variables amplitude. 


\subsubsection{Rule Writing (Construct If / Then values)}

Write the obvious rules first. Then write the less obvious but intuitively correct rules next. Finally write the unobvious rules through introspection and experience. Select intersection, inference, aggregation, and defuzzification methods based on the constraints of computational speed, memory use, and information preservation. Here the system have two inputs. With seven linguistic variables in each range, we obtain 49 rules. A typical rule has the following structure:

\section{If $e$ is NB AND e is PB then $u$ is $z$}

Where, $u$ is the output of fuzzy controller. Now it is required to find the fuzzy region for the output for each fuzzy rule using the maximum - minimum method [14]. The AND operator means finding minimum between $\mu$ (e) and $\mu$ (e). Then the output of the above rule can be obtained using the minimum value between $\mu$ (e) and $\mu$ (e), which called the degree of applicability. Then find the output membership function of the above rule using the crisp value of the calculated degree of applicability by clipping the corresponding fuzzy set. Finally, find the output membership function due to all of these fuzzy sets. This is can be attained by knowing the membership function of the fuzzy controller, which is transformed back into the crisp value through the defuzzifier to control the plant. Its output signal ' $\mathrm{U}_{\mathrm{g}}$ ' is to added as a supplementary control signal at the input of the speed governor control loop shown in figure 1.

\subsubsection{Simulation and tuning}

Adjust membership functions and rules to achieve desired model performance. Computer simulation and / or testing on the target system may be necessary. Visualization techniques and commercially available tools aide this area of fuzzy engineering significantly.

\subsubsection{Translate of Model to Target System}

This step deals with how the simulated and tuned fuzzy model is implemented in the user application. Design trade-off considers speed, memory, and complexity. We also looked at variety of hardware and software implementation issues.

\subsubsection{Integration of Fuzzy Model into User Application}

This final step pointed out that a fully developed fuzzy model is still not a stand alone solution. Additional elements may be needed to complete the user application including interfaces, exception handling, operator alerting, and collection of performance data

\section{SIMULATION STUDIES}

To examine the effectiveness of the proposed fuzzy logic governor controllers in damping the system oscillations, time simulations have performed on the nonlinear system with the proposed control technique. The IEEE 9 - bus multimachine power system shown in figure $\mathbf{5}$ is used with those simulations. This system consists of one hydro-machine and two steam-machines, which are mutually coupled. Each of those three generators are equipped with turbine speed governors and exciters provided with 
AVR. The parameters of all generators, governors, exciters, AVR, transmission lines, loads and operating conditions are given in reference [15] and Appendix A.

All generators are assumed to be either equipped with the proposed fuzzy controller or equipped with conventional controller on governor control loop for comparison purposes. Due to the different sizes of the generators and system configuration, multioscillations occur when the system is subjected to disturbances. In order to observe this fact two-study cases were performed. Details of the two disturbances are as follows:

\section{Case 1: System Performance After Three-Phase Faults}

A three phase short circuit disturbance at bus number 9 is applied for $100 \mathrm{~ms}$ at $\mathrm{t}=$ $1 \mathrm{sec}$. and removed with successful reclosure. The transients were simulated during ten seconds.

\section{Case 2: System Performance After Three-Phase Fault With Line Opening}

A three phase short circuit disturbance at bus number 9 is applied for $100 \mathrm{~ms}$ at $\mathrm{t}=1 \mathrm{sec}$., and cleared by removing line $4-9$. The system time response is simulated during ten seconds.

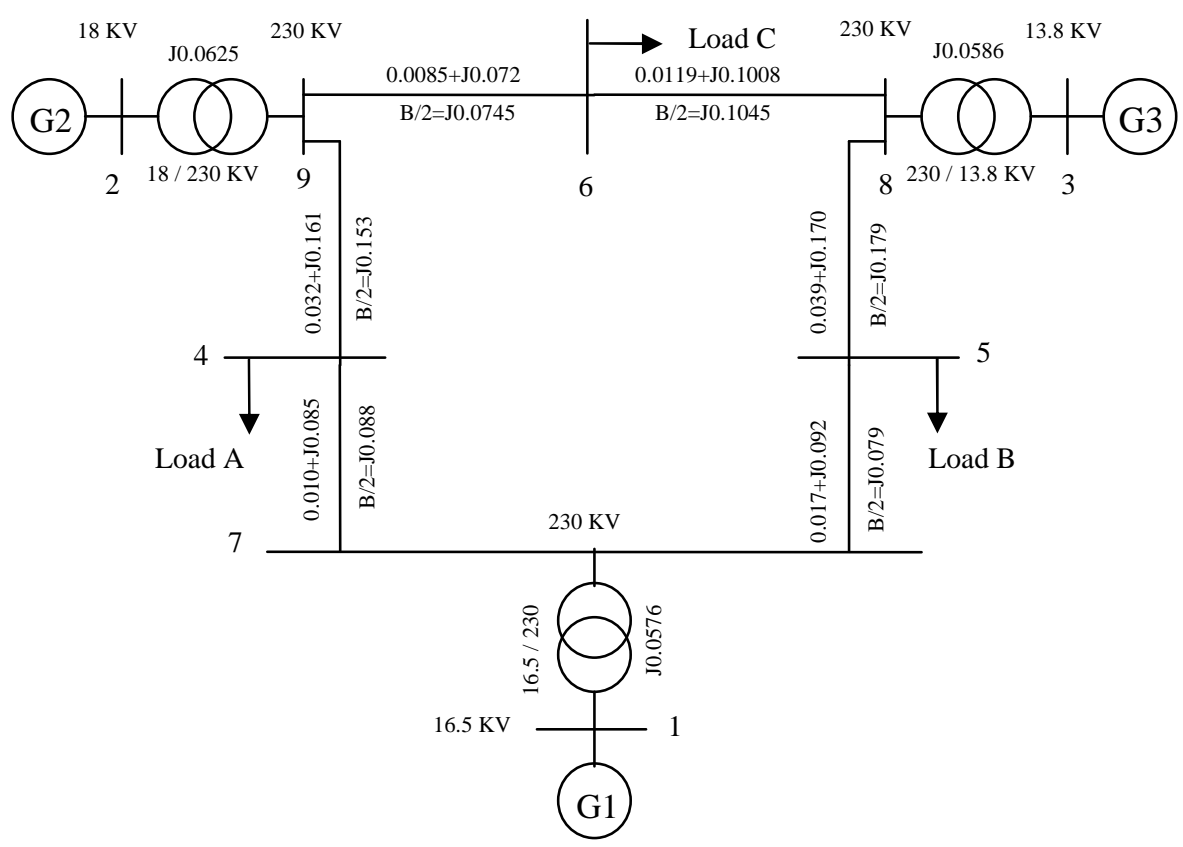

Fig. 5: Multimachine power system.

\section{RESULTS AND DISCUSSION}

To demonstrate the effectiveness of the proposed controller, several simulations were performed with turbine speed governor with conventional controller and with fuzzy logic controller. The transient response of the power system generators when 
provided by turbine speed governor and equipped with the fuzzy logic controller and conventional controller are plotted in the figures. Figures $\mathbf{6}$ and $\mathbf{7}$ show simulated results of the rotor angle $\delta_{12}$ and $\delta_{13}$ respectively while figures 8 and $\mathbf{9}$ show the same simulated results of the rotor speed deviation. It can be seen from those responses that the fuzzy controller offers a good performance and predict the system dynamic accurately. By comparing responses corresponding to the new fuzzy logic controller, with that when the conventional controller is applied, it can be seen that the system transient performance, under large disturbances, is highly improved. The improvement is due to the addition of large amount of positive damping to the summing point of the turbine speed governor control loop.

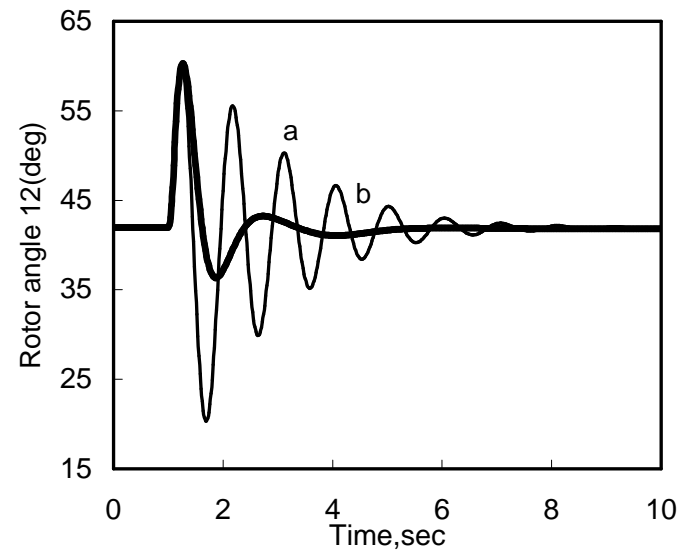

Fig. 6: Rotor angle 12 (study case 1).

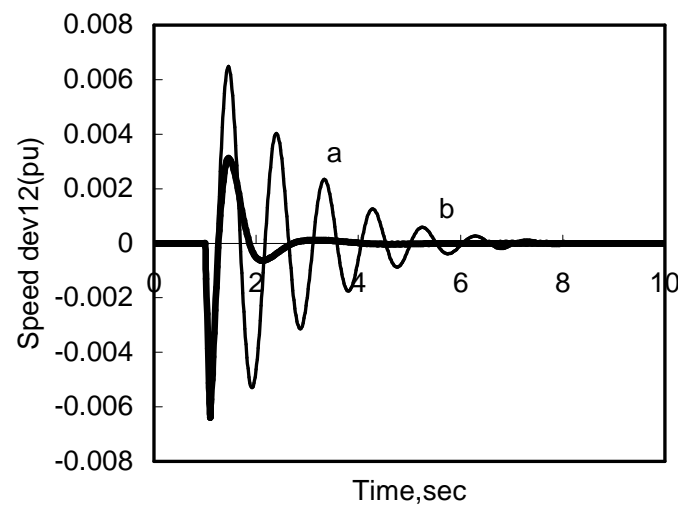

Fig. 8: Rotor speed 12 (study case1).

(a) With conventional controller,

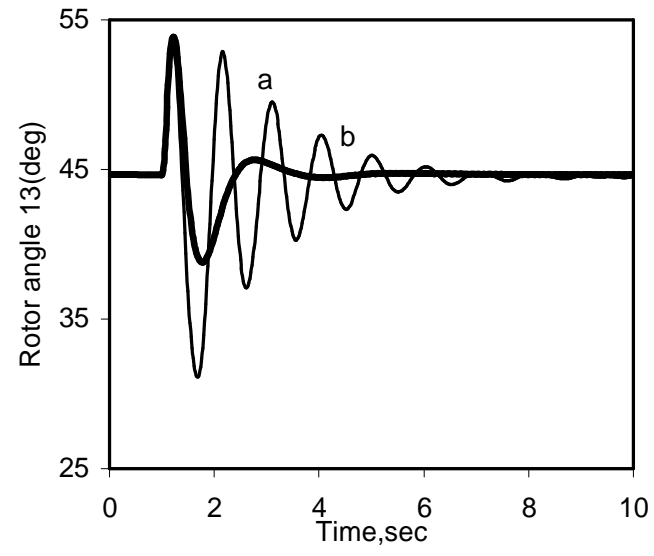

Fig. 7: Rotor angle 13 (study case1).

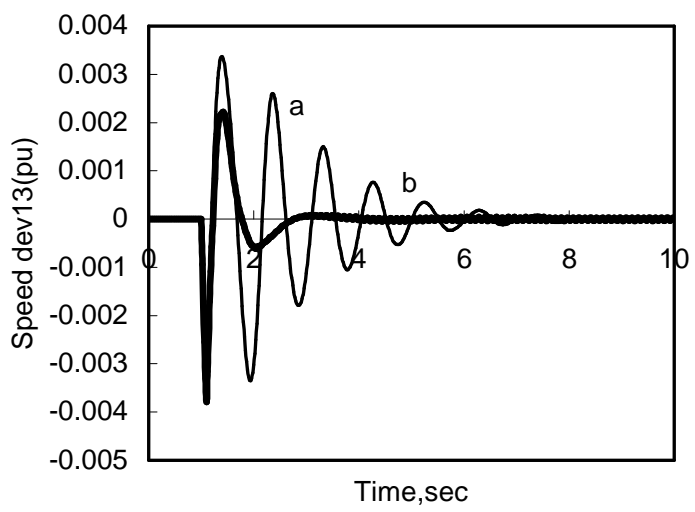

Fig. 9: Rotor speed 13 (study case1).

(b) With fuzzy logic controller

Figures 10-13 show the simulated results of the study case 2 . In this case the power system becomes radial and the amount of the positive damping obtained from the conventional controller is not enough while it is sufficient in the case of fuzzy controller. 


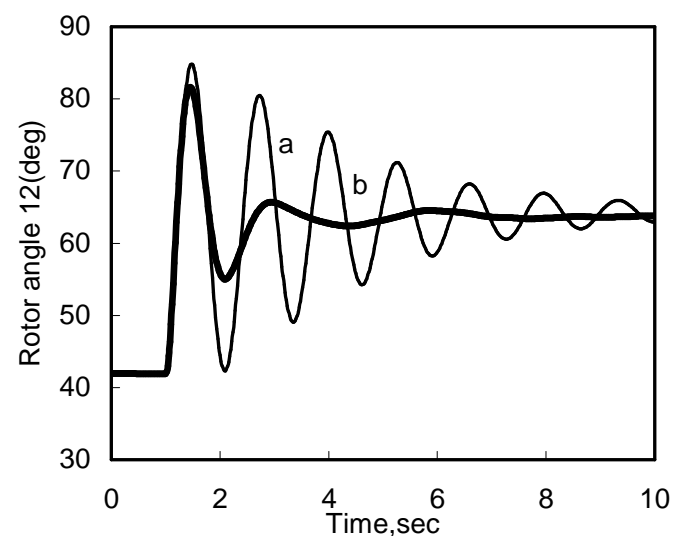

Fig. 10: Rotor angle 12 (study case2).

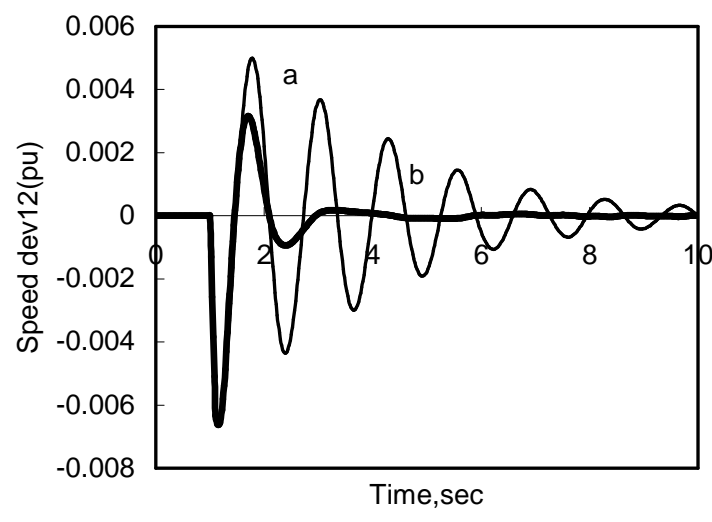

Fig. 12: Rotor speed 12 (study case2).

(a) With conventional controller,

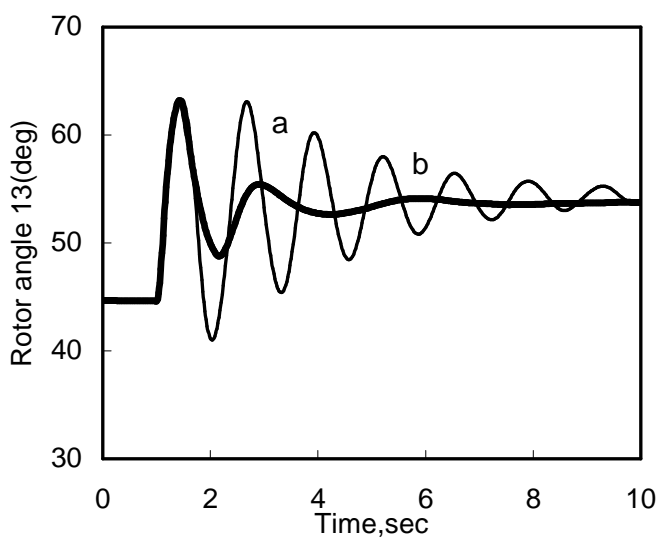

Fig. 11: Rotor angle 13 (study case2).

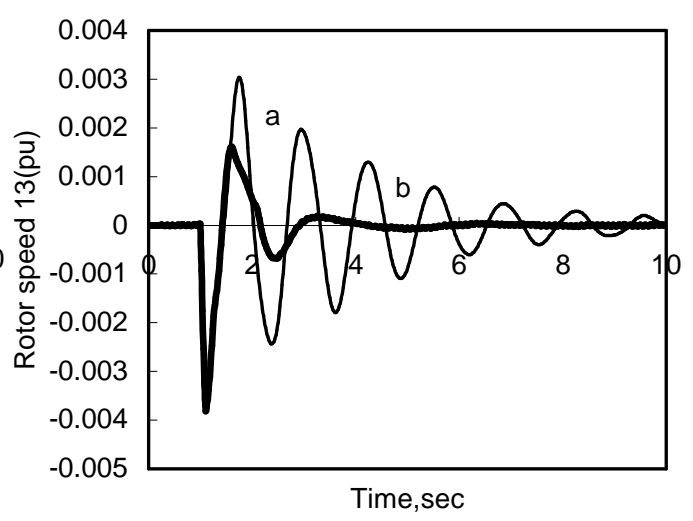

Fig. 13: Rotor speed 13 (study case2).

(b) With fuzzy logic controller

\section{CONCLUSIONS}

1. A new controller based on fuzzy set theory has been suggested to be injected as a supplementary control signal at the turbine speed governor control loop, in multimachine power system comprising hydraulic and steam power plants.

2. Nonlinear system time simulation responses have demonstrated that the proposed controller is capable of improving the transient system performance after different disturbances. The digital simulation results proved the effectiveness of the proposed fuzzy logic controller over conventional controller when they are applied to the turbine speed governor.

3. The decentralized output feedback control law developed requires local measurements within each generating machine and the proposed fuzzy controller is very simple for practical implementation. Finally, the availability of electro hydraulic governors and fast turbine valving has now made it possible to obtain very fast turbine response, with the proposed fuzzy logic controller. 


\section{REFERENCES}

[1] Mlodrag B. Djukanovic Mlan S. Calovic, 'Neuro - Fuzzy Controller of Low Head Hydropower Plants Using Adaptive - Network Based Fuzzy Inference System', IEEE on Energy Conversion, Vol.12, No.4, Dec. 1997, pp. 375 - 381.

[2] Djordj M. Dobrijevic and Marko V. Jankovic, 'An Approach to the Damping of Local Modes of Oscillations Resulting from Large Hydraulic Transients', IEEE Trans. on EC, Vol.14,No.3, Sept. 1999, pp. $754-759$.

[3] M. Mahmoud, K. Dutton, M. Denman, 'Multivariable Fuzzy Controllers for Three Hydraulically Coupled Turbines', The Mediterranean Journal of Measurement and Control, Vol.1, issue 1, pp. 18-28, 2005.

[4] Ragaey A.F.Saleh, 'Transient Stability Enhancement of a Fully Superconducting and Damperless Generator Using Governor Loop', MEPCON'2003, Menoufiya University, Shebin EL - Kom, Egypt 2003, pp. 107 - 112.

[5] G.Shabib Ashraf M. Hemeida, 'Application of Self Tuning Fuzzy PID Controller for Multimachine Power Systems', MEPCON'2003, Menoufiya University, Shebin EL - Kom, Egypt 2003, pp. 119 - 124.

[6] H.A.Khattab, G. A. Morsy, S. M. Osheba and A. M. Kinawy, 'Fuzzy PI Controller for a Superconducting Generator', MEPCON'2003, Menoufiya University, Shebin EL - Kom, Egypt 2003, pp. 301 - 305.

[7] M.Z.EL - Sadek, 'Power Systems Control', Book, Muchtar Press, Assiut, Egypt 2004.

[8] R.Podmore, 'Power System Dynamic Simulation Program - User Manual', Department of Electrical Engineering, University of Saskatchewan, Jan. 1974.

[9] F.P.deMello, P. J. Nolan, T. F. Laskowski and J. M. Undrill, 'Coordinated Application of Stabilizers in Multimachine Power System', IEEE Trans. on Power Apparatus and System, Vol. PAS - 99, No.3, May / June 1980.

[10] IEEE Committee Report,' Dynamic Models for Steam and Hydroturbines in Power System Studies ', IEEE Trans. Vol. PAS-92, pp. 1904-1915, Nov./Dec. 1973.

[11] Les Pereira, John Undrill, Dmitry Kosterev, Donald Davies and Shawn Patterson, 'A New Thermal Governor Modeling Approach in the WECC', IEEE Trans. on Power Systems, Vol.18, No.2, May 2003.

[12] Lei Jing.Luquing Ye, O. P. Malik, Y. Zeng, 'An Intelligent Discontinuous Control Strategy for Hydroelectric Generating Unit', IEEE Trans. on Energy Conversion, Vol.13, No.1, March 1998, pp. 84 - 89.

[13] Ted Heske,Jill Neporent Heske, 'Fuzzy Logic for Real World Design', Book, Annabooks, San Diego, USA, 1999.

[14] I.Ljung, 'An Introduction to Fuzzy Control', Book, Spring - Verlag 1993.

[15] P. W.Sauer and M. A. Pai, 'Power System Dynamics and Stability', Book, Prentice Hall 1998. 


\section{APPENDIX A}

The Power System Models:

Synchronous Machine Model:

$$
\begin{aligned}
\mathrm{V}_{\mathrm{q}} & =\mathrm{E}_{\mathrm{q}}^{\prime}-\mathrm{X}_{\mathrm{d}}^{\prime} \mathrm{I}_{\mathrm{d}}-\mathrm{R}_{\mathrm{a}} \mathrm{I}_{\mathrm{q}} \\
\mathrm{V}_{\mathrm{d}} & =\mathrm{E}_{\mathrm{d}}^{\prime}+\mathrm{X}_{\mathrm{q}}^{\prime} \mathrm{I}_{\mathrm{q}}-\mathrm{R}_{\mathrm{a}} \mathrm{I}_{\mathrm{d}} \\
\dot{\mathrm{E}}_{\mathrm{q}} & =\left(\mathrm{E}_{\mathrm{fd}}-\mathrm{E}_{\mathrm{q}}^{\prime}-\left(\mathrm{X}_{\mathrm{d}}-\mathrm{X}_{\mathrm{d}}^{\prime}\right) \mathrm{I}_{\mathrm{d}}\right) / \mathrm{T}_{\mathrm{d} 0}^{\prime} \\
\dot{\mathrm{E}}_{\mathrm{d}} & =\left(-\mathrm{E}_{\mathrm{d}}^{\prime}+\mathrm{E}_{\mathrm{q}}^{\prime}-\left(\mathrm{X}_{\mathrm{q}}-\mathrm{X}_{\mathrm{q}}^{\prime}\right) \mathrm{I}_{\mathrm{q}}\right) / \mathrm{T}_{\mathrm{q} 0}^{\prime} \\
\dot{\omega} & =\left(\mathrm{P}_{\mathrm{m}}-\mathrm{P}_{\mathrm{e}}-\mathrm{P}_{1}-\mathrm{D} \omega\right) / 2 \mathrm{H} \\
\dot{\delta} & =2 \pi \mathrm{f}_{\mathrm{o}} \omega \\
\mathrm{T}_{\text {elec }} & =\mathrm{E}_{\mathrm{d}}^{\prime} \mathrm{I}_{\mathrm{d}}-\mathrm{E}_{\mathrm{q}}^{\prime} \mathrm{I}_{\mathrm{q}}-\left(\mathrm{X}_{\mathrm{d}}^{\prime}-\mathrm{X}_{\mathrm{q}}^{\prime}\right) \mathrm{I}_{\mathrm{d}} \mathrm{I}_{\mathrm{q}}
\end{aligned}
$$

Excitation System Model:

$$
\begin{aligned}
& \dot{\mathrm{E}}_{\mathrm{fd}}=\left(-\mathrm{E}_{\mathrm{fd}}+\mathrm{K}_{\mathrm{A}}\left(\mathrm{V}_{\text {ref }}-\mathrm{V}_{\mathrm{t}}-\mathrm{V}_{\mathrm{f}}\right)\right) / \mathrm{T}_{\mathrm{A}} \\
& \dot{\mathrm{V}}_{\mathrm{f}}=\left(\mathrm{T}_{\mathrm{f}} \dot{\mathrm{E}}_{\mathrm{fd}}-\mathrm{E}_{\mathrm{fd}}\right) / \mathrm{K}_{\mathrm{f}}
\end{aligned}
$$

The Mathematical Models for Governing System:

Steam Turbine Governor Model:

$$
\begin{aligned}
\dot{\mathrm{y}}_{\mathrm{HP}} & =\left(\mathrm{g}-\mathrm{y}_{\mathrm{HP}}\right) / \mathrm{T}_{\mathrm{HP}} \\
\dot{\mathrm{y}}_{\mathrm{IP}} & =\left(\mathrm{y}_{\mathrm{HP}}-\mathrm{y}_{\mathrm{IP}}\right) / \mathrm{T}_{\mathrm{IP}} \\
\dot{\mathrm{y}}_{\mathrm{LP}} & =\left(\mathrm{y}_{\mathrm{IP}}-\mathrm{y}_{\mathrm{LP}}\right) / \mathrm{T}_{\mathrm{LP}} \\
\dot{\mathrm{g}} & =\left(\left(\left(\omega_{\mathrm{ref}}-\omega\right) / \mathrm{R}\right)-\mathrm{g}\right) / \mathrm{T}_{\mathrm{S}} \\
\mathrm{P}_{\mathrm{m}} & =\mathrm{F}_{\mathrm{HP}} \mathrm{y}_{\mathrm{HP}}+\mathrm{F}_{\mathrm{IP}} \mathrm{y}_{\mathrm{IP}}+\mathrm{F}_{\mathrm{LP}} \mathrm{y}_{\mathrm{LP}}
\end{aligned}
$$

Hydraulic Turbine Governor Model:

$$
\begin{aligned}
& \dot{\mathrm{g}}=-\left(\omega-\omega_{\text {ref }}+\alpha+\sigma \mathrm{g}\right) / \mathrm{T}_{\mathrm{S}} \\
& \dot{\alpha}=-\delta\left(\omega-\omega_{\text {ref }}+\alpha+\sigma \mathrm{g}\right) / \mathrm{T}_{\mathrm{S}}-\alpha / \mathrm{T}_{\mathrm{R}} \\
& \dot{\mathrm{P}}_{\mathrm{m}}=2\left(\left(\mathrm{~g}-\mathrm{P}_{\mathrm{m}}\right) / \mathrm{T}_{\mathrm{W}}-\dot{\mathrm{g}}\right)
\end{aligned}
$$

Conventional Controller Model:

$$
\dot{\mathrm{U}}_{1}=-\mathrm{U}_{1} / \mathrm{T}_{1}+\Delta \dot{\omega} \mathrm{K} / \mathrm{T}_{1}
$$




$$
\begin{aligned}
& \dot{\mathrm{U}}_{2}=\left(1-\mathrm{T}_{2} / \mathrm{T}_{1}\right) \mathrm{U}_{1} / \mathrm{T}_{3}-\mathrm{U}_{2} / \mathrm{T}_{3}+\Delta \dot{\omega} \mathrm{KT}_{2} / \mathrm{T}_{1} \mathrm{~T}_{3} \\
& \dot{\mathrm{U}}_{\mathrm{C}}=-\mathrm{U}_{\mathrm{C}} / \mathrm{T}_{3}+\left(1-\mathrm{T}_{2} / \mathrm{T}_{3}\right) \mathrm{U}_{2} / \mathrm{T}_{3}+\left(1-\mathrm{T}_{2} / \mathrm{T}_{1}\right) \mathrm{U}_{1} \mathrm{~T}_{2} / \mathrm{T}_{3}^{2}+\Delta \dot{\omega} \mathrm{KT}_{2}^{2} / \mathrm{T}_{1} \mathrm{~T}_{3}^{2}
\end{aligned}
$$

Multimachine Power System Parameters, All Data in pu and Time Constant sec:

Table 1 Synchronous Machine Data

$\begin{array}{lccc}\mathrm{G} \# & 1 & 2 & 3 \\ \text { Rated MVA } & 247.5 & 192 & 128 \\ \text { Rated KV } & 16.5 & 18 & 13.8 \\ \text { Rated P.F } & 1 & 0.85 & 0.85 \\ \text { Type } & \text { Hydro } & \text { Steam } & \text { Steam } \\ \text { Speed } & 180 \mathrm{r} / \mathrm{min} & 3600 \mathrm{r} / \mathrm{min} & 3600 \mathrm{r} / \mathrm{min} \\ \mathrm{X}_{\mathrm{d}} & 0.146 & 0.8958 & 1.3125 \\ \mathrm{X}_{\mathrm{d}} & 0.0608 & 0.1198 & 0.1815 \\ \mathrm{X}_{\mathrm{q}} & 0.0969 & 0.8645 & 1.2578 \\ \mathrm{X}_{\mathrm{q}}^{\prime} & 0.0969 & 0.1969 & 0.25 \\ \mathrm{X}_{1} & 0.0336 & 0.0521 & 0.0472 \\ \mathrm{r}_{\mathrm{a}} & 0.0016 & 0.0026 & 0.0035 \\ \mathrm{~T}_{\mathrm{d} 0}^{\prime} & 8.96 & 6.0 & 5.89 \\ \mathrm{~T}_{\mathrm{q} 0}^{\prime} & 1.5 & 0.535 & 0.6 \\ \mathrm{D} & 0.3073 & 0.8489 & 0.85 \\ \mathrm{H} & 23.64 & 6.4 & 3.0\end{array}$

Table 2 Automatic Voltage Regulator Data

$\begin{array}{lccc}\mathrm{G} \# & 1 & 2 & 3 \\ \mathrm{~K}_{\mathrm{A}} & 400 & 400 & 400 \\ \mathrm{~T}_{\mathrm{A}} & 0.05 & 0.05 & 0.05 \\ \mathrm{~K}_{\mathrm{F}} & 0.025 & 0.025 & 0.025 \\ \mathrm{~T}_{\mathrm{F}} & 1 & 1 & 1 \\ \mathrm{~V}_{\text {RMAX }} & 5.3 & 5.3 & 5.3 \\ \mathrm{~V}_{\text {RMIN }} & -5.3 & -5.3 & -5.3\end{array}$

Table 3 Power System Stabilizer Data

$\begin{array}{lccc}\mathrm{G} \# & 1 & 2 & 3 \\ \mathrm{~K} & 10 & 20 & 20 \\ \mathrm{~T}_{1} & 10 & 0.03 & 0.03 \\ \mathrm{~T}_{2} & 0.57 & 1.5 & 1.5 \\ \mathrm{~T}_{3} & 0.10 & 0.14 & 0.14 \\ \mathrm{U}_{\text {MAX }} & 0.12 & 0.12 & 0.12 \\ \mathrm{U}_{\text {MIN }} & -0.12 & -0.12 & -0.12\end{array}$

Table 4 Loads Data

$\begin{array}{llccc} & & \text { Load A } & \text { Load B } & \text { Load C } \\ \mathrm{P}_{\text {o }} & \text { MW } & 125.0 & 90.0 & 100.0 \\ \mathrm{Q}_{0} & \text { MVAR } & 50.0 & 30.0 & 35.0\end{array}$


Table 5 Network Data

\begin{tabular}{|c|c|c|c|c|}
\hline Bus & Jo. & Impeda & & Susceptance \\
\hline From & to & $\mathrm{R}$ & $X$ & $\mathrm{~B} / 2$ \\
\hline 1 & 7 & 0.0 & 0.0576 & \\
\hline 2 & 9 & 0.0 & 0.0625 & \\
\hline 3 & 8 & 0.0 & 0.0586 & \\
\hline 7 & 4 & 0.01 & 0.085 & 0.088 \\
\hline 4 & 9 & 0.032 & 0.161 & 0.153 \\
\hline 9 & 6 & 0.0085 & 0.072 & 0.0745 \\
\hline 6 & 8 & 0.0119 & 0.1008 & 0.1045 \\
\hline 8 & 5 & 0.039 & 0.17 & 0.179 \\
\hline 5 & 7 & 0.017 & 0.092 & 0.079 \\
\hline
\end{tabular}

Table 6 Turbine and Governor Data:

$\begin{array}{lcll}\mathrm{T}_{\mathrm{R}} & 5.0 & \mathrm{R} & 5.0 \\ \mathrm{~T}_{\mathrm{S}} & 0.04 & \mathrm{~T}_{\mathrm{S}} & 0.15 \\ \delta & 0.3 & \mathrm{~T}_{\mathrm{HP}} & 0.4 \\ \sigma & 0.05 & \mathrm{~T}_{\mathrm{IP}} & 5.8 \\ \mathrm{~T}_{\mathrm{W}} & 1.0 & \mathrm{~T}_{\mathrm{LP}} & 0.5 \\ \mathrm{~g}_{\text {MAX }}^{\prime} & 0.1 & \mathrm{~F}_{\mathrm{HP}} & 0.3 \\ \mathrm{~g}_{\text {MIN }}^{\prime} & -0.1 & \mathrm{~F}_{\mathrm{IP}} & 0.4 \\ & & \mathrm{~F}_{\mathrm{LP}} & 0.3\end{array}$

\section{تحسين الأداء العابر باستخدام محكم السرعة المبنى على الأكاء الصناعي}

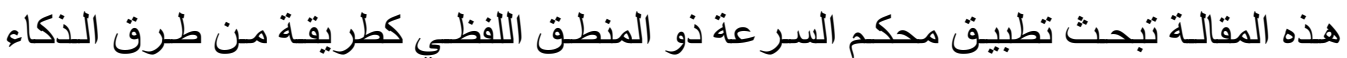

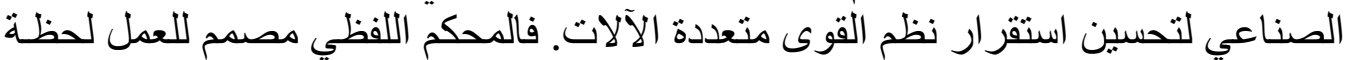

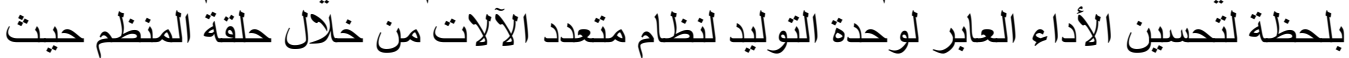

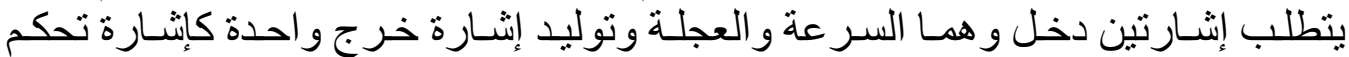

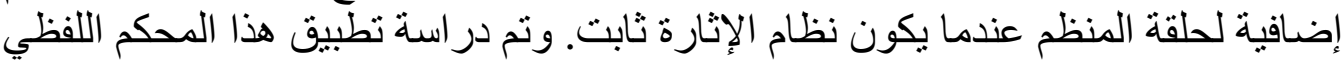

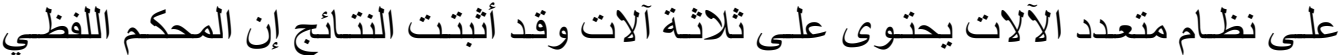

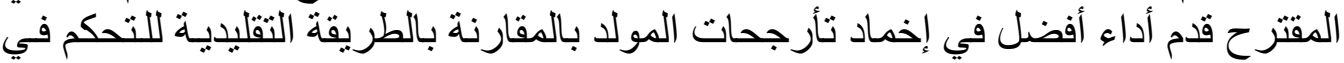

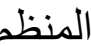

